\title{
World Health Organization's Global Strategy on diet, physical activity and health: the process behind the scenes
}

\author{
Kaare R. Norum \\ Department of Nutrition, Medical Faculty, University of Oslo, Norway
}

Abstract

Some aspects of the difficulties and politics behind the making of a World Health Organization (WHO) Global Strategy on Diet, Physical Activity and Health are described. The main resistance came from sections of the food industry selling products high in sugar and salt. The article describes how these industries were lobbying both directly to the WHO and indirectly via member states. Their aim was to stall the work on the WHO Global Strategy; however, the Global Strategy was endorsed at the World Health Assembly in May 2004.

Keywords: diet and health; food industry; food policy; non-communicable diseases; nutrient intake; physical activity; salt; saturated fats; sugar; World Bank; World Health Organization

\section{Background}

In May 2004 the Word Health Assembly endorsed a Global Strategy on Diet, Physical Activity and Health (GS). I was involved in the process of shaping the strategy, and this article is a personal view on how the strategy was formed. My task was to be the Chair for a Reference Group that would help the World Health Organization (WHO) headquarters to make up a document on the strategy. The reference group consisted of 12 international experts on diet, physical activity and public health.

The reason for forming a GS was the severe increase in non-communicable diseases (NCDs) all over the world. This had been documented yearly by the WHO, and most clearly in the 2002 World Health Report (1), which showed that about $60 \%$ of all deaths in the world are from NCDs and that the increase is most prominent in the developing world. The people afflicted in the developing world are younger than those in the better off countries. The World Health Report 2002 also revealed that several of the most important risk factors behind the NCDs were connected with diet, smoking and physical activity. In other words, many of the risk factors and the NCDs were preventable.

\section{Expert review of the scientific basis for recommendations of nutrient intake}

The problem of the increase in NCDs was first discussed at the WHO in 2000, when a resolution about the problem was endorsed. It was on the agenda again in 2001, and in 2002 it was decided that WHO should form a GS, and that the document should be discussed at the World Health Assembly (WHA) in 2004. The WHO headquarters had 2 years to compose the GS. It started by setting up an expert committee to go through the research and science behind the relationships between diet, nutrients and health.

The expert committee, which consisted of 30 members from around the world, was chaired by Richardo Uauy, a professor in paediatrics and nutrition from Chile. The committee used more than 100 other scientists as consultants and peer reviewers. The result of this committee was WHO Technical Report Series 916 (TRS 916), "Diet, nutrition and the prevention of chronic diseases" (2). It was released in April 2003. Before then, drafts of the report were made public on the Internet so that other experts, industry and other stakeholders could comment and react. Thus, the process of creating TRS 916 was open and translucent and peer reviewed. TRS 916 gave population nutrient 
intake goals for preventing diet-related chronic diseases. The recommendation for intake of basic nutrients was the same as recommended by the WHO in 1990, in TRS 747 (3).

\section{Reaction of the food industry to the recommendations in TRS 916}

TRS 916 provoked reactions from parts of the food industry. The most serious came from the sugar industry and its associations, but the salt industry and palm oil producers also protested. Since TRS 916 was regarded as the scientific platform for the GS, the reactions against the report influenced the whole process of forming the GS. Resistance against the GS was kept up until the last minute at the WHA in May 2004.

The palm oil industry reacted against the recommendation about intake of saturated fat. These reactions led to some modifications in the GS, since palm oil is an important part of the diet in some tropical developing countries. The protest from the Salt Institute was not taken into serious consideration; it was a concerted action together with the sugar industry.

The sugar industry and its associations protested heavily, and wrote angry and threatening letters to Gro Harlem Brundtland, then Director General at the WHO.

They also wrote to the US Minister of Health, Secretary Tommy Thompson, and asked him to not pay the US contribution to the WHO if TRS 916 was published with the recommendation about the intake of free sugars being less than $10 \%$ of daily energy intake. The sugar industry claimed that there were no scientific data that could be used to set a limit of $10 \%$ energy, that TRS 916 was written by selected experts and that the report was not peer reviewed, and not sent out for comments from the industry before it was published. None of these objections was true, and the report was released in Rome by the Director Generals of both the WHO and the Food and Agriculture Organization (FAO).

Concomitantly with the work with TRS 916, WHO headquarters began work on the draft for the GS. At the start of the process, it was considered very important to consult with many member states in all of the WHO regions, and with several other stakeholders.

The secretariat and members of the reference groups had meetings in all six WHO regions, to which a large number of member states was invited. These meetings provided a large amount of information and other types of input for forming a GS. The problems concerning NCDs varied in the different regions, but every country, including those in Africa, had increasing problems with NCDs. Many member states, however, had a double burden of disease, with part of the population being afflicted with different types of NCD and other parts having diseases due to infections and lack of healthy food.

The delegates to the WHO regional meetings were mainly from the health sector, and therefore more general problems, e.g. trade and price policy, were not dealt with seriously at these meetings. This lack of more general politicians at the regional meetings turned out to be a problem at a later stage in the making up and acceptance of the GS. The reasons were that both the GS and accepting the recommendations in TRS 916 had, for some countries, e.g. Brazil, huge consequences for the production of and trade in sugar.

A hint as to what was going on behind the scenes was revealed during a meeting of RIMSA at the Pan-American Health Organization (PAHO) in April 2003. This meeting, which was held in Washington DC, was the biannual meeting between the Ministries of Agriculture and Health in the American countries.

I was asked by the WHO headquarters to give a talk about TRS 916 and about the process concerning the ongoing work with the GS.

I was told that my presentation was scheduled to take $1 \mathrm{~h}$, including discussion. This was the schedule until a few days before the meeting, but 2 days before the meeting I was told by the PAHO to shorten my presentation to $10 \mathrm{~min}$. These changes in the programme were made because, I was told, that more time should be allowed for discussion, because the "sugar issue" had been much in the media, and the delegates needed more time for questions, answers and discussion. Then, shortly before my scheduled talk, I was told that there should be no discussion afterwards. My understanding was that since some topics in the WHO/FAO report had become a "hot and not so sweet" political issue, the delegates, who were mainly from the health and agriculture sectors, were probably lacking instructions from their governments on how to respond to the content of the report, especially the "sugar issue". It was, however, 
obvious that this change had happened in response to pressure from the Sugar Association or industry groups. Furthermore, someone from the Grocery Manufactures of America (GMA) had an official paper at the meeting, in which the GMA heavily criticized TRS 916. The agenda seemed to be arranged so that it was not possible for the WHO to respond to this paper. I wrote to the Director General of PAHO, with a copy to Gro Harlem Brundtland, that I was surprised that a person from the American food industry has access to a PAHO meeting and could criticize the WHO, without PAHO providing a formal basis for WHO to correct misunderstandings and to respond to the criticism.

\section{Expanded lobbying process: influence of the "concerned industry" on member states}

Meetings took place in Geneva with other organizations in the United Nations (UN) family, with international non-governmental organizations (NGOs) and with the private sector, both with the major companies and with their associations. The consultations provided a lot of valuable information and input into the strategy, but also revealed the forces that were opposing such a strategy. The NGOs made several valuable suggestions on how to make effective measures, and stressed the importance of controlling and collaborating with the private sector. The private sector, however, stressed that the problem with NCDs was mainly a problem for individuals, and that the food industry was only making and offering food products that the consumers demanded. They claimed that there are no bad foods, only bad diets, and these were due to personal choices. The strongest resistance against forming a GS came from the Sugar Association and the snack-making industry, which used TRS 916 in their criticism of the GS. They wrote to the US Minister of Health, Secretary Thompson, and asked for withdrawal of the US financial support to the WHO because of the recommendations in TRS 916. The intensity of the lobbying process was clearly shown by similar reactions being written to Secretary Thompson by the Corn Refiners' Association, International Dairy Foods Association, National Corn Growers' Association, Snack Food Association, Sugar Association, Wheat Foods Council and US Council for International Business. Letters to Secretary Thompson from two US Senators, Larry
E. Craig and John Breaux, supported the industry initiative.

Concomitantly with what happened in the WHO headquarters, the industry organizations were active in many developing countries producing sugar and palm oil. The industry lobby groups tried to convince the countries that if the GS was endorsed and TRS 916 was valid as a basis for the GS, then that could seriously influence the financial status of the country. In a meeting in Geneva with the WHO team and "Group 77 [G77] and China" (a collaborating group of developing countries within the UN), the questions regarding sugar and palm oil were again raised. The countries producing palm oil were concerned because TRS 916 recommended less saturated fat in the diet. It was interesting to note that at the meeting the delegates used the same wording in their arguments as the industry has used in their letters to the countries. The discussions were dominated by questions relating to trade and economics, not health issues, even though many of these countries, e.g. Mauritius and Brazil, had huge health problems with obesity and diabetes in their populations.

It was obvious that the WHO's initiative trying to prevent NCDs in the world by forming a GS evoked a lot of serious political issues, which were strongly connected with international industry and trade.

\section{Discussion of a draft version of the Global Strategy by the WHO Executive Board}

The work with the GS, however, went on as planned by the WHO, and a draft of the GS were sent to the member states in November 2003, so that the GS could be discussed at a meeting of the WHO Executive Board (EB) in January 2004. Before the EB meeting extensive lobbying from the Sugar Association took place. The most prominent result of that process was a letter to the WHO from the US Department of Health and Human Services, signed by the senior adviser to Secretary Thompson, William Steiger. This letter was mainly concerned with TRS 916, but was sent immediately before the EB. The letter delivered a message that appeared, in effect, to seek to stall the development of a GS on diet, activity and health due for consideration at the WHO EB meeting. The arguments in the letter were a carbon copy of what the Sugar Association had previously used against the WHO. I was so upset with the message 
in the letter that I wrote an open letter to Secretary Thompson.

I quote some key parts of the letter:

"... There is an extensive body of sound scientific research now available, which supports the case for immediate action across the whole of society to improve dietary health through the reduction in the consumption of foods containing high levels of fats, added sugars and salt and also soft drinks containing high volumes of caloric sweeteners. The submission made by your Department appears in some interpretations to contradict this and to focus solely on a critique of a single document, the WHO Report on Diet, Nutrition and the Prevention of Chronic Diseases, prepared by an expert group of leading world authorities.

... It is significant that resistance from business interests, which included the sugar industry and soft drinks manufacturers with US government support, was also demonstrated when a previous WHO expert report, based on a scientific consultation in 1990, made similar recommendations intended to prevent diet-related chronic diseases.

... What has happened to Americans since then? Obesity rates have risen so that now one in three Americans bears the burden of the very high health risks associated with this condition, with the poorest and most vulnerable sectors of society worst affected. The evidence from your own expert advisers now highlights the cluster of risk factors known as the metabolic syndrome which affected one third of the American adolescents who were overweight or obese in the early 1990s. Obesity rates among American children have risen by $50 \%$ since then. There are now three times as many overweight adolescents as there were in 1980. Using the US census data for the year 2000, it is estimated that about 47 million US residents have the metabolic syndrome. Some of them are the young people whose future health and wellbeing was left a hostage to fortune when US government and business interests declined to act on the earlier WHO report on the prevention of chronic diseases...".

This letter was extensively covered in the main global newspapers and the reactions to it, both in the USA and globally, changed the attitude of the US delegation at the EB meeting.

Nevertheless, at the Geneva meeting there was clear evidence of considerable lobbying taking place, with sugar-dependent countries voicing concerns that reflected the language and specific detailed objections of the sugar industry representatives. At the EB meeting several developing countries stated concern about their economy and trade if there were to be a limit in the global consumption of sugar. The irony in the political arguments was best illustrated by Mauritius. This sugar-producing developing country has a seriously high incidence of morbid obesity and diabetes, and has official dietary guidelines of eating less than $10 \%$ of energy from sugar. However, at the EB meeting Mauritius was, owing to trade and economic reasons, against that limit of sugar intake on a global scale.

In January 2004, after considerable discussions, the WHO EB agreed to forward the draft of the WHO GS on Diet, Physical Activity and Health to its WHA, after allowing countries an extended period, until 29 February 2004, for comments. A final draft strategy was to be considered by WHO member states in May 2004.

\section{The FAO's fight against TRS 916 and the Global Strategy}

The sugar associations did not give up their lobbying against the sugar limit. The World Sugar Research Organization undertook its own analysis and sought to convince small producers in lowincome developing countries that their entire industry would decline even further if the standing recommendation on limiting sugar consumption were applied.

The role of the sugar lobby became more explicit at the FAO Committee on Agriculture (COAG) meeting in Rome in February 2004, with sugarinspired criticisms, which again falsely criticized the make-up of the expert group (in fact, it had significant representation from developing countries), the alleged lack of peer review (in fact, there was a clear peer-review process) and the alleged lack of consultation (despite the public consultation process involving governments, private sector, experts and civil society).

The COAG meeting, where a written paper combined analysis of TRS 916 and the GS, was faced with an orchestrated "ambush", with statements from developing countries hostile to the report as well as from representatives of the sugar industry. The G77 and China combined in a statement supported by GRULAC, the Latin American and Caribbean group, voicing strong opposition. 
Subsequently, it emerged that these statements were not wholly authorized by governments, but were locally determined. China later expressed its support for the GS, while the G77 group has convened its own working group to reconsider the position. Brazil, which chaired the G77 chapters in Geneva, had unresolved internal differences, with its health ministry expressing public support for the strategy.

The sugar industry continued to lobby vociferously and said that it was working with the broader food industry "to ensure that science guides the proper drafting of the WHO's GS for consideration by the World Health Assembly in May 2004". This was a reference to removing the association of TRS 916 from the strategy and avoiding any suggestion that the consumption of added sugars should be limited, and thus implied continued opposition to the proposals.

The World Bank published its own study at the same COAG meeting, demonstrating that it was the trade distortions caused by annual subsidies worth US \$6.4 billion to Western sugar producers that were suppressing world market prices and denying small growers a $40 \%$ increase in their incomes (4). An opening of protected markets would lead to an extra one million jobs in the sugar industry in developing countries. Thus, the World Bank paper on Sugar Policy stated that the real dangers for developing countries were subsidies and trade barriers. The agricultural and trade policy, not health, was now at the forefront of the discussion.

\section{From a draft strategy to full endorsement of a Global Strategy on Diet, Physical Activity and Health}

WHO received 57 submissions about changes, some large and many minor, from member states (5). Several of the changes contained important suggestions, most of them with general support for the GS. Based on the drafts, the EB discussions and the submissions, the WHO secretariat made up the final document for the WHA. The discussion concerning the recommendations in TRS 916 continued in the period between the EB meeting and the WHA. The WHO secretariat was under pressure to reduce the importance of TRS 916 as a scientific platform for the GS, especially the sugar issue. Several of the scientists behind TRS 916 and in the WHO
Reference Group for the GS were concerned about the pressure on the WHO.

Despite these concerns, TRS 916 was not mentioned in the text of the Resolution and its annex, the document containing the GS. The final work on the GS in the WHO headquarters reflected the very sparse support for this strategy from the Director General and his office. It was, furthermore, as a result of this that the most important people working with the GS, Derek Yach and Pekka Puska, had left the WHO.

The GS was discussed thoroughly at the WHA. Most of the discussion was about the same issues that had been discussed by the EB: scientific basis and reference to specific nutrients, individual responsibility, implications for the agriculture sector, undernutrition, pricing policies (e.g. taxes, subsidies), marketing to children and the role of industry.

Production and trade, especially concerning sugar, underwent the most lengthy and difficult discussions. The discussion took part between lawyers and trade politicians, not between health professionals. Some issues concerning trade and agricultural issues were taken into the Resolution about the GS. The Strategy Document (6) was not changed; a great victory for global public health. However, the last remaining reference to TRS 916, a single small footnote in the annex, was excised to allow the GS to survive the final stage at the WHA in May. Yet TRS 916 is now an officially accepted WHO Technical Report. The strategy's rather bland recommendation to limit the intake of free sugars should allow the use of TRS 916 to set the limit.

\section{Implementation of the Global Strategy}

The task is now to implement the strategy. This must take place locally, regionally and globally. There is much to be done by each WHO member state. Fiscal measures and regulations need to be decided by each country's government. The WHO headquarters has decided that much of the implementation procedures and work must be done regionally. However, coping with international food companies and issues such as international regulation of marketing to children need to be settled by international negotiations, and the WHO has an important role in these processes. On each level in the implementation process it is important to understand that public health will only improve if there is constant and hard pressure at 
every step. Thus, it is vital to keep up the pressure for a better diet and more physical activity nationally, regionally and globally. In these process consumers' organizations have important roles to play, and the media have to be mobilized. We must not to become lost in complexity, but need to hang on to the big picture, probably by using sugars as a symbol, since this is easy for both the general public and politicians to grasp. It is, however, important to understand that the problems not only relate to the health sector, but also need a comprehensive solution. This requires collaboration with several ministries, NGOs, the media and the private sector. In this respect, we should not accept powerful industry lobbies saying that the problems should be solved by individuals and not by the industry. However, it is important to work together with those in the private sector, showing real responsibility for public health. Last, but not least, it is essential for all sectors, concerned media and responsible industry to build health into daily life, through both diet and physical activity.

\section{References}

1. World Health Organization. World Health Report: reducing risks, promoting healthy life. Geneva: WHO; 2002.

2. World Health Organization/Food and Agriculture Organization. Diet, nutrition and the prevention of chronic diseases. Report of a joint WHO/FAO expert consultation. WHO Technical Report Series 916. Geneva: WHO; 2003.

3. World Health Organization. Diet, nutrition and the prevention of chronic diseases. Report of a WHO study group. WHO Technical Report Series 797. Geneva: WHO; 1990.

4. World Bank. World Bank Policy Research Working Paper 3222. Washington DC: World Bank; 2004.

5. www.who.int/hpr/gs.strategy.country.shtml

6. www.who.int/gb/ebwha/pdf_files/WHA57/A57_R17en.pdf

Professor Emeritus Kaare R. Norum

Department of Nutrition

Medical Faculty

University of Oslo

Norway

E-mail: k.r.norum@basalmed.uio.no 